\title{
Successful ESL Writing for Publication: The Role of Writers' Autonomy, Linguistic Competence and L1/L2 Critical Reading Skills
}

\author{
Natalia Smirnova \\ National Research University Higher School of Economics
}

Correspondence concerning this article should be addressed to Natalia Smirnova, National Research University Higher School of Economics, Kantemirovskaya, 3A, St. Petersburg, Russian Federation, 194100.

E-mail: natas2002@yandex.ru

\begin{abstract}
The main aim of the research is to examine professional L1 (Russian)/L2 (English) writing experiences among staff members of one Russian research-intensive university as well as to provide more insights into the universal pedagogies of professional writing. The empirical paper focuses on assessing writers' ability to reflect upon linguistic competence, independent L1/L2 writing skills and L1/L2 critical reading issues which help multilingual scholars position themselves as successful writers in L1 and L2. Text-based semi-structured interviews aimed at measuring self-assessed overall writers' autonomy in L1/L2, linguistic competence and critical reading skills in their L1/L2 writing experience were conducted. The key findings include L1/ L2 writing features and support the idea that successful professional and autonomous writing seems to be closely related to a set of one's metalinguistic competences, defined in this paper as a critical reading competence, once a certain level of L2 proficiency has been achieved. The paper concludes with some pedagogical implications in the field of writing for publication.
\end{abstract}

Keywords: writing for publication, multilingual scholars, critical reading, autonomy, reflective writing strategy, English as lingua franca

'Publish or perish' pressure has been increasingly experienced by most researchers all over the world (see e.g. Lillis \& Curry, 2010; Miller, Taylor \& Bedeian, 2011). At the same time, writing for publication itself has become a separate field of studies. Various lines of research into this field suggest that there are a number of factors which can foster/hinder successful writing for publication in English among non-native scholars.

In 1990s, studies in the field were mostly related to the role of linguistic competence in English among non-native speakers (NNS) (writers), while a decade later, other metalinguistic competences and writing for publication practices came to the relevant research surface. Currently, such issues as access to resources, disparities in journals and pedagogies of professional writing have been addressed within the international academic community.

\section{Materials and Methods}

\section{The Role of Linguistic Competence in Professional Writing}

Earlier studies in the UK (Shaw, 1991) and USA contexts (Casanave \& Hubbard, 1992; Jenkins, Jordan, \& Weiland, 1993) focused on English language proficiency importance over metalinguistic factors and defined it as the key factor to success among NNS academic writers. Numerous studies have been carried out in the field of corpus linguistics and discourse analysis of professional writing (Swales, 1981, 1990, 2000, 2004; Jaroongkhongdach et al., 2012) and in the field of English as the lingua franca of the academic world (Jenkins, Cogo, \& Dewey, 2011; Mauranen, 2011). These studies show that research articles in English- 
medium journals by NNS have various features (e.g. author's stance, hedging/boosting, etc.).

According to more recent research, readerfriendliness of a paper appears to be more challenging goal for NNS writers who use English proficiently (Armstrong, 2011). However, what it takes to produce a text which is both coherent and cohesive is treated by writers differently. The present study relates this ability to one's metalinguistic skills such as recognizing research genres, article structure, and discipline-specific reasoning patterns.

Studies in local contexts of NNS scholars carried out in Japan (Gosden, 1995, 1996) and Hong Kong (Flowerdew, 1999a, 1999b) highlighted such difficulties for writers as the time involved in writing a paper in English, poor English vocabulary, inference of native language (L1) in the process of writing in English (L2). These findings suggest that the set of metalinguistic skills also include one's awareness of L1/L2 inference in two secondary discourses of research writing in their native and English languages.

This paper suggests that the set of developed metalinguistic competences might result in autonomous professional writing when a writer has reached a certain level of English language proficiency. Critical reading of publications ability in L1/L2 constitutes a set of the required metalinguistic competencies, and is important in an NNS writer's successful research writing endeavors.

\section{Access to Key Resources in Writing}

Apart from having good academic English skills and being aware of the L1/L2 inference, research conducted into the centre vs periphery scholars' experiences in the process of knowledge production revealed some crucial inequality issues (e.g. getting access to resources such as funding, research facilities, access to paid databases, English language itself which "belongs" to Anglophones) (Canagarajah, 1996, 2002; Curry \& Lillis, 2004, 2010). Further research includes studies on center-periphery scholars' practices in 5 European countries (Curry \& Lillis, 2010), Poland (Duszak \& Lewkowicz, 2008), Venezuela (SalagerMeyer, 2008), Sudan (ElMalik \& Nesi, 2008), Italy (Giannoni, 2008), Korea (Dong, 2009), Baltic sea region (Hogan-Brun et al., 2008). Findings from these studies also indicate that scholars' experiences vary across contexts and access to recourses influences their academic success (including writing for publication practices).

English is treated as lingua franca in the academic community though it "belongs" to Anglophone countries, and the language itself has become a resource and a means of accessing research data in the global scale. This fact means that NNS research writers should be aware of and have access to networking (including co-writing) with their foreign peers in the field, proofreading done by native speakers (NS) as well as English language proficiency which makes NNS scholars capable of reading/analyzing/critically interpreting the internationally published research in English. The broader and more permanent access to resources is, the more successful (Curry \& Lillis, 2010) and, as a result, more independent writing for research purposes is.

\section{Disparities in Journals}

Along with the above-mentioned issues of the level of language proficiency, power relations and access to resources, a few studies focus on disparities in English-medium (seen as publication outlets). Flowerdew (2001, 2008) explored intelligibility of a researcher's local community along with issues of the English language proficiency. The findings indicate that the stronger a scholar's country research base is, the greater publication output is present in the global research scholarship. These findings also suggests that a researcher's integration into global research community implies drawing on the key research findings by international scholars and comparing/ contrasting local research findings to the global ones. Still, journals might value local scholarship differently (and in some cases unequally) (Curry \& Lillis, 2010).

Editing one's text is seen as another factor which influences writing for publication practices (Flowerdew, 2001; Gosden, 2003; Li, 2006; Belcher, 2007; Li \& Flowerdew, 2007). The main findings are indicative of the fact that provision of editorial service (editing and polishing) is crucial for NNS writers. Their willingness to participate in a long process of paper revision is also seen to be important. Thus, fulfillment of all the editorial requirements for improving one's paper results in a greater publication output in English-medium journals of an NNS scholar.

\section{Pedagogies of Professional Writing: From Critical Reading to Autonomous Writing}

Research findings in the field of professional writing triggered development of various pedagogical models. Swales, Feak and Hixson (2000) developed a self-study guide which introduces rhetorical moves strategy for writing abstracts, introductions, and literature reviews. One more approach targets scholars' linguistic knowledge together with their knowledge about inequalities in access to resources and power relations in scholarly writing (Curry \& Lillis, 2013). Yet, little attention has been given to the role of autonomous writing competence and its subskills in successful writing for publication. 
The present paper, in addressing the issue of successful professional writing, suggests that one's linguistic competence and a set of metalinguistic competences lead not only to better writing skills but also to higher independence in an NNS researcher's process of writing. In other words, writers should be aware of and be able to independently work with their papers on the text level (linguistic competence) and produce reader-friendly manuscripts (i.e. demonstrate an ability to identify moves in a text, hedging, boosting, etc.). L2 professional writing researchers also should be able to apply different forms of feedback which encourage and facilitate the process of writing (Hyland \& Hyland, 2006; Armstrong, 2011).

It seems that another approach to teaching research writing on the basis of developing of a certain type of the reading competence might be suggested and the set of metalinguistic competencies defined in this paper seem to be closely related to critical reading competence.

Critical reading can be broadly defined as one's ability to critically engage with a text and understand hidden assumptions and implications under its surface. Pascarella and Terenzini (1991) conclude that in most cases this critical competence includes the following abilities: to identify an argument and important relationships in a text, make data-based inferences and conclusions, and evaluate authority in a text. On the whole, many scholars and education specialists follow the definition and offer their interpretations of the concept for a particular academic setting and educational goals .

In order to measure one's critical reading ability defined as high-order cognitive skill (Burden \& Byrd, 1994) a set of sub-skills and strategies are specified. For a good reader it is necessary to distinguish between facts and opinions and relevant from irrelevant claims and information. It is also critical to be able to determine if a statement is accurate, non-ambiguous and strong as well as to decide if a source is credible. Finally, critical reading means one's ability to identify assumptions and detect bias and logical fallacies.

It seems that critical reading competence with the context of higher education is commonly related to two domains. The first one is connected to non-discipline specific vs discipline-specific reading. The former means reading for understanding any text content, key ideas, assumptions and implications made by its author (Appendix 1) while the latter incorporates reading in a particular discipline, selecting proper sources and reading for developing one's research process (Appendix 1). These approaches, undertaken by subject teachers at a university, usually do not focus on the linguistic side of how the key elements of critical reading competence, are expressed in L2 writing by the NS author.
By contrast, the second domain of critical reading skills integration is related to the field of teaching English as second or other Language (TESOL) where teaching is primarily related to reading for understanding common (widely applied) linguistic framing of such issues as research results or literature review, as well as identifying academic vocabulary and academic grammar, text structure, and writer's opinion. It seems that this approach fails to take into account the content and relevance of a particular disciplinary text for the reading goals of a particular scholar who is learning the skill of writing his/her own research results in a particular field.

Critical reading serves two purposes which, in the field of teaching writing for publication, might be possibly integrated into one critical reading competence for discovering important information in a text and how it is expressed from a linguistic point of view, i.e. both at the linguistic level and at the metacognitive level. The developed reading competence might further foster more advanced research writing skills if reading into writing TESOL approaches are undertaken (see for example, http:// qoo.by/2u2U).

The following section of the paper investigates the degree of development of research writing competence, which comprises three main components (writer's autonomy, linguistic competence and critical professional reading skills) among NNS writers.

\section{Research Methodology. Research Context}

The University is a leading University. Although it is a relatively young institution (only 20 years old), it has undergone a number of development stages from being a purely educational body to becoming a pioneering national research university. In 2013, the government launched a contest '5/100' and invited institutions to compete for additional government funding. The main aim of the initiative was to select five leading Universities across Russia which could become competitive in the international higher education market by the year 2020, and to provide them with substantial financial support so that they can join the world top ratings of Universities (see http://expert.ru/ural/2012/38/5-100-2020/).

Once the university was granted the status of a research center in 2007, all the staff members were strongly advised to publish their research papers in English in order to join the global academic community. Publication activity of its staff has also become the key criterion of the assessment of the effectiveness of the University and its employees. The University has been toughening employment policy requirements and scholars are increasingly expected to submit their findings to established and Scopus or Web of 
Science indexed journals which are considered to be at the highest level of scientific research publishing hierarchy.

At the same time, most researchers, who have substantial experience in successfully publishing their papers in Russian, feel rather stressed. Issues that scholars commonly raise in everyday discussion include the following: lack of knowledge and skills of good academic writing in English for scientific purposes, 'too local' research design framework which does not contribute to the global research agenda, lack of academic literacy(ies), unawareness and fear of (or resistance to) the nature and laws of global academic community are just a few of the factors (reasons) which make publishing in English a great challenge to the NRU HSE scholars. Among the abovementioned obstacles, critical reading of published L2 research in one's field is only occasionally rated by scholars as a core skill for successful witting in L2 and it seems that not all researchers are aware of its importance.

\section{Respondents}

This study was carried out within the NRU HSE, St. Petersburg. Sixteen scholars, who met the B2 English competence benchmark, and enrolled for attending modules in academic writing run by the Department of Foreign Languages, participated in the research. The respondents had different academic/research backgrounds and came from various disciplines (Sociology, Economics, Management, and Philosophy). The respondents are equally distributed across the four disciplines which allow making relevant compare/ contrast analysis of interview results.

The majority of the respondents held a Russian $\mathrm{PhD}$ equivalent and had no experience of studying for a degree abroad. On the whole, they were active L1 writers who had more than eight published papers in Russian. All the researchers had little experience in L2 research writing (see Figure 1) and were novice writers.

\section{Research Methods. Data Collection}

\section{Semi-structured Interviews}

In accordance with the main aim, the following approach and methodology were used. A semistructured interview was chosen in order to learn more about the NNS writers' experiences and related skills and it was administered to 16 faculty members at the university. The interview was carried out in English (which was the medium of instruction) and integrated in the course structure with an extra goal of promoting writers' self-reflection on their writing practices. An interview guide was developed with the aim to learn about scholars' writing for publication experiences, their writing autonomy, linguistic competence, and critical reading abilities both in L1 and L2. The reader-friendly text concept (Armstrong, 1986), writing feedback issue and the reading in the discipline competence became the basis for developing the guide.

The interview guide consisted of two main parts and four sections. The first one includes two sections with items relating to the positive/negative experiences of autonomous writing for publication in L1/L2 and questions about perceptions of one's linguistic competence in L2 and its role in successful writing up the research in English. The third section focuses on the writers' $\mathrm{L} 1 \mathrm{critical}$ reading strategies and practices.

The second part of interview questions (Section 4) were text-based (an English-medium research article from a particular field) and helped to learn about researchers' L2 writing and reading experience (including an ability to identify moves (Swales, 2000), an ability to reflect upon audience, purpose, style, text structure, hedging, positioning yourself as a writer in L2, using evidence vs. example).

Data analysis

The data from interviews was transcribed using MS Word application and coded in Excel in accordance with the key interview questions for its further analysis. For example, critical reading competence in L2 was coded as "Can do/ can't do" statements across such components as abilities in identifying moves in LR, hedging, boosters, writer's opinion, genre, arguments (reasoning thread), premises and

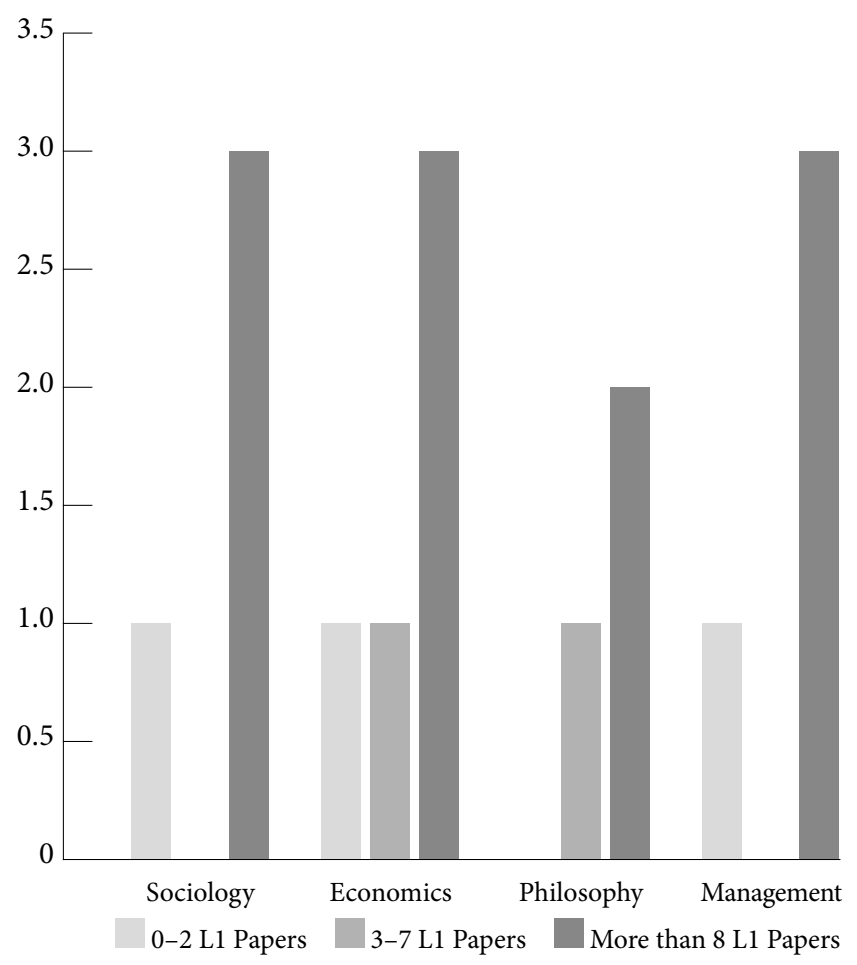

Figure 1. Number of L1 publications in each discipline. 
conclusions, descriptions, background information, explanations, text relationships (cause-effect, sequence, chronological, problem-solution), databased inferences and conclusions, thesis statement, evidence and examples.

\section{Results and Discussion}

\section{Autonomy in Writing}

Overall, the majority of scholars (12 people) confirmed their highly developed L1 writing skills as well as marked lack of independent L2 writing for publication skills. The results revealed some interesting local traditions in research writing in L1. Feedback in L1 writing is mostly related to formal editing of a text and meeting journal's publication requirements (paper structure, referencing style, etc.) rather than to revising the paper content. Independent writing in their native language was commonly explained by one's Russian language competence and experience in research writing in the course of study for their PhD. Postgraduate study and awareness of disciplinary thinking patterns helped the writers' to easily do referencing as well as making claims and assumptions in their Russian texts.

All the interviewees confirmed their experience in collaborative writing and its benefits in terms of timeefficiency and access to resources ("journal editor personal contacts", "a fee for publishing a text"). The majority of respondents proofread their papers themselves and rarely had their L1 text proofread by a peer as they saw no need in it ("do not fancy this idea", "feel insecure" or "do not trust"). Finding an appropriate outlet was marked as not a difficult one, and the only obstacle was "a substantial fee for publication" or "lack of close contacts with the editor".

By contrast, writing in L2 seems to be a far challenging task. All the interviewees said that they were not able to proofread their text in English, find a proper journal for publication. The majority of writers emphasized that following referencing requirements and developing key arguments are highly difficult ("I usually write "I think or we believe" to express my opinion). Collaborative writing was unknown experience for the writers and only two interviewees had a little experience in dealing with feedback provided by NS reviewers. The majority of the interviewees expressed their concerns with the lack of access to such resources as NS proofreading and subject specific critical reviewing of the paper content.

Only four interviewees mentioned the importance of knowing publishing strategies such as "how to find a journal", "how to deal with reviewers", and "personal attitude - fear and stress of being rejected" while the majority of respondents' answers (13 people) confirmed that that they needed to develop their writing skills in
L2. On the whole, the results showed that the majority of respondents were experienced L1 (Russian) researchers and writers with very little experience in L2 writing for publication.

\section{Linguistic Competence}

The linguistic competence interview section revealed that the majority of scholars "can write" and they "know English grammar and have good vocabulary knowledge". The majority of interviewees emphasized that professional vocabulary and writing in English in the discipline seemed to be difficult but they can produce a research text with a certain structure and a suggested title. The key concern expressed by the writers was that they did not know how to check if the research text met the required L2 writing standards and what these standards were (common comments were "I did not study for a degree abroad to know the writing requirements").

Overall, all of the interviewees stated that "it is the English language competence which makes you a successful writer" which is mostly the results of one's experience of studying for a research degree (which includes learning how to write up research results) in the UK or the USA. Despite good English language proficiency, the majority of respondents (14 scholars) stated that their texts did not look "native and polished" and were written in "Russian English".

\section{Critical Reading Skills}

The interview results supported the idea that the writers have advanced L1 critical reading skills and are able to identify text structure, the way authors develop their arguments, signal about important claims, premises and conclusions. However, five interviewees stated that in some cases it was difficult to understand and identify in a Russian research text the writer's purpose ("hard to find the central claim", "messy ideas"). One interesting finding is related to citing practices of L1 writers. The majority of interviewees said that they could reference any research texts or monographs and no one treated referencing as a strategy for increasing their paper acceptance chances in a particular journal. One more interesting finding of the present study was that writers were not aware of hedging and boosting in their native language and did not treat them as important in their writing.

The set of interview text-based questions (an English-medium research article from one's field) helped to learn about the researchers' L2 reading experience and skills. The majority of the scholars (15 people) demonstrated their ability to reflect upon audience, define the purpose and the style of the paper. Descriptions, explanations and text relationships of 
cause-effect, sequence, and chronological were also easily distinguished by the majority of interviewees. However, only two interviewees were able to identify moves in the Literature Review section. Only one scholar paid attention to the author's hedging and positioning and identified their linguistic framing.

However, a number of key challenges were identified. They included the identification of a writer's opinion and argumentation thread as well as a thesis statement in the paper (with a common comment "I understand all the words in the paragraph but I still can't see the point"). Finally, the majority of interviewees failed to evaluate authority in the given text. They also stated that it was hard to say if the works cited by the author were reliable and that they rarely referred to L2 texts when they wrote L1 research papers. One interviewee explained that "I draw on the substantial research base generated in Russia in my filed and why should I refer to any international research papers which are produced in a different country and research environment".

It seems that critical reading skills posed various levels of difficulty to the NNS writers and that the writers, despite their advanced L1 reading competence and substantial experience in L1 research and its writing, required support in developing their L2 critical skills of understanding a text both at the linguistic and metalinguistic levels. The interview results support the idea that autonomous L2 critical reading skills are required by scholars in order to be able to perceive/ produce reader-friendly texts which mostly means to have syntactic awareness and metacognitive reading strategies (Nergis, 2013). In other words, it is suggested that autonomous L2 academic writers should master the whole range of critical reading competence components and as a result they will be able to recognize disciplinary genre and incorporate its patterns into their own L2 texts.

\section{L1 vs L2 Professional Writing}

Some interesting findings were revealed in relation to writing in a discipline. The writers in the fields of Sociology, Economics and Management shared very similar L1 vs L2 writing perceptions and attitudes and differed from writers in the field of Philosophy. Both Scholar A and Scholar B (an economist and philosopher, respectively) admitted it was their inability to understand/make hidden assumptions, clear logical reasoning, find/define bias rather than their English language competence which did not allow them to be autonomous writers. For example, Scholar A mentioned: "I know all the words in the sentence but I still cannot understand what he (author) means in this case." Both scholars stated that this difficulty did not allow them to write "high-quality papers".

Another finding was that L1 writing tradition was interfering with L2 writing style and approach. Scholar
B responded: "It seems to me that I write in "Russian" English. I mean my papers look Russian and I do not know how to explain it". Scholar A expressed the same concern that he tended to write his L2 papers similarly to L1 style. The NS reviewers' feedback on his texts was mostly related to style rather than to linguistic choice. L1 writing is aimed at only specialists in a scholar's field and L1 articles seem to be very specialized and not for a general reader. It is "the job" of the reader to understand the text and hear the writer's voice.

The interview session also helped reveal some not only disciplinary conventions in professional writing but also differences in L1 and L2 professional writing (see Table 3). It is clear that Economics and Philosophy are two different fields of studies with their own research genres and styles. Of particular interest will be the differences within one discipline but in L1 and L2 discourses.

Scholar B's answers provide more insights into professional writing. A text title to a text in L1 serves to draw attention of the reader and is described as "provocative" while in L2 context it is rather formal. This feature is also reflected in the text structure. It is important both to follow the fixed structure of a text and a style of writing when you "play with the reader". Interestingly, the number of references in an L1 text will be quite fixed (ten references per page) while in L2 the writer should make a rational choice of when and what to refer to. L1 texts tend to be impersonal (no I/ we) with the lots of hedges with the aim to give credit to the existing scholars' works and "not be arrogant". By contrast, though L2 texts are full of hedges they serve a different purpose and help the writer to provide some room for discussion.

Scholar A's answers also revealed a number of L1/L2 differences in writing for publication. The $\mathrm{L} 2$ title serves to draw the attention of the reader while L1 title is quite formal in its style. The text structure seems to be more comprehensive in an L2 article as it also includes the discussion section with the critical contribution to the field. Referencing patterns seem to be similar in both discourses as well as the impersonal style of writing. Hedging patterns are also very similar which might be explained by the fact that disciplinary writing in L1 has imported L2 writing genres in Economics (as well as in Sociology and Management).

The research findings showed similar results to the study by Armstrong (2011) and Hyland and Hyland (2006) that an ability to produce L2 reader-friendly texts is the next challenge after English language competence for NNS scholars. A particular focus should be made on developing an NNS writer ability to differentiate between L1 and L2 research discourses and be aware of general research writing standards as well as of particular disciplinary similarities/differences in research texts. 


\section{Conclusion}

The main aim of the research was to examine professional L1/L2 writing competences among staff members of a university as well as to make some pedagogical suggestions in the field of NNS professional writing. The paper suggests that autonomous writing skills, linguistic competence and L2 critical reading competence should be developed to produce written texts of a particular genre in a particular discipline.

Overall, the research results show that the NNS scholars lack an ability to independently work with their papers on the text level (linguistic competence) and produce reader-friendly manuscripts (a set of metalinguistic competencies related to one's L2 critical reading skills of professional texts). L2 professional writing researchers also fail to apply different forms of L2 feedback though it is a key prerequisite which encourages and facilitates the process of writing (Hyland \& Hyland, 2006; Armstrong, 2011). Finally, the interview results reveal that the writers are not always aware of and are not able to effectively use key resources for L2 high quality writing.

The paper suggests that poor L2 critical reading skills should be developed so that researchers will first learn to perceive a written text and later to produce written texts of a particular genre in a particular discipline. L2 writing competence is closely related to one's ability to critically engage with an academic text written not only in L2 but also in L1. As a result researchers are able to fully convey their research story in L2.

Although the study results seem to support the hypothesis of the importance of mastering autonomous writing skills, acquiring an advanced linguistic competence, and developing L2 critical reading skills for successful L2 writing for publication, a larger-scale research with a bigger sample needs to be conducted in order to have a better understanding of the positive impact of development of all the three components. It would also be necessary to incorporate a TESOL test method component in order to receive an objective measurement of one's linguistic, reading and writing competence and compare test results with the selfassessed writers' skills.

The research findings have implications for developing pedagogies of research writing which could be applied to TESOL and are relevant to the Russian geocultural setting (Velikaya, 2008). In particular, a teaching "writing for publication" model should include the development of a list of critical competencies with three sections. The first one should comprise independent writing skills and strategies such as applying feedback, revising and editing and choosing a publication outlet. The next section should incorporate a set of English for Specific Academic Purposes (ESAP) knowledge and skills relevant within a researcher's field with particular disciplinary conventions in research writing. Finally, extended critical reading in L2, as a set of sub-skills (e.g. developing a thesis statement, argumentation thread, paragraphing, hedging, etc.) should be developed for a particular disciplinary discourse as well as skills of differentiating between L1 and L2 research discourses and their effective application in one's professional writing. The defined set of competencies might become the basis for creating a new reading into writing teaching framework and developing a self-study manual for NNS professional writers.

Overall, the research findings are important for a number of reasons. First, conducting the research within the Russian geo-cultural space seems to be challenging and provides more insights into the complex issue of professional academic writing in English. Second, the research provides more research data on L1 and L2 roles in professional writing within a parallel language environment and about the academic bilingualism among modern Russian scholars (Mezek, 2013).

\section{References}

Armstrong, C. (1986). Reader-Based and writer-based perspectives in composition instruction. Rhetoric Review, 5(1), 84-89.

Armstrong,T. (2011). Reader-Friendliness and feedback: German-L1 scholars' perceptions of writing for publication in English. Journal of Academic Writing, 1(1), 153-164.

Belcher, D. D. (2007). Seeking acceptance in an Englishonly research world. Journal of Second Language Writing, 16(1), 1-22.

Burden, P., \& Byrd, D. (1994). Teaching; Effective teaching. Boston, MA: Allyn and Bacon.

Canagarajah,A.S.(1996). "Nondiscursive" requirements in academic publishing, material resources of periphery scholars, and the politics of knowledge production. Written Communication, 13(4), 435-472.

Canagarajah, A. S. (2002). Multilingual writers and the academic community: Towards a critical relationship. Journal of English for Academic Purposes, $1(1), 29-44$.

Casanave, C. P., \& Hubbard, P. (1992). The writing assignments and writing problems of doctoral students: Faculty perceptions, pedagogical issues, and needed research. English for Specific Purposes, 11(1), 33-49.

Curry, M. J., \& Lillis, T. (2004). Multilingual scholars and the imperative to publish in English: Negotiating interests, demands, and rewards. TESOL Quarterly, 38(4), 663-688.

Curry, M. J., \& Lillis, T. (2013). A scholar's guide to getting published in English. Practical choices, critical 
strategies. Clevedon, UK: Mutilingual Matters.

Dong, W. C. (2009). Science journal paper writing in an EFL context: The case of Korea. English for Specific Purposes, 28, 230-239.

Duszak, A., \& Lewkowicz, J. (2008). Publishing academic texts in English: A Polish perspective. Journal of English for Academic Purposes, 7(2), 108-120.

ElMalik, A. T., \& Nesi, H. (2008). Publishing research in a second language: The case of Sudanese contributors to international medical journals. Journal of English for Academic Purposes, 7(2), 87-96.

Flowerdew, J. (1999a). Writing for scholarly publication in English: The case of Hong Kong. Journal of Second Language Writing, 8(2), 123-145.

Flowerdew, J. (1999b). Problems in writing for scholarly publication in English: The case of Hong Kong. Journal of Second Language Writing, 8(3), 243-264.

Flowerdew, J. (2001). Attitudes of journal editors to non-native speaker contributors. TESOL Quarterly, 35(1), 121-150.

Flowerdew, J. (2008). Scholarly writers who use English as an additional language: What can Goffman's "Stigma" tell us? Journal of English for Academic Purposes, 7(1), 77-86.

Giannoni, D. S. (2008). Medical writing at the periphery: The case of Italian journal editorials. Journal of English for Academic Purposes, 7(2), pp. 97-107.

Gosden, H. (1995). Success in research article writing and revision: A social-constructionist perspective. English for Specific Purposes, 14(1), 37-57.

Gosden, H. (1996). Verbal reports of Japanese novices' research writing practices in English. Journal of Second Language Writing, 5(2), 109-128.

Gosden, H. (2003). 'Why not give us the full story?': Functions of referees' comments in peer reviews of scientific research papers. Journal of English for Academic Purposes, 2(2), 87-101.

Jaroongkhongdach, W., Todd, R. W., Keyuravong, S., \& Hall, D. (2012). Differences in quality between Thai and international research articles in ELT. Journal of English for Academic Purposes, 11(3), 194-209.

Hyland, K., Hyland, F. (Eds.). (2006). Feedback in second language writing: Contexts and issues. Cambridge, UK: Cambridge University Press.

Jenkins, S., Jordan, M. K., \& Weiland, P. O. (1993). The role in writing of graduate engineering education: A survey of faculty beliefs and practices. English for Specific Purposes, 12(1), 51-67.

Jenkins, J., Cogo, A., \& Dewey, M. (2011). Review of developments in research into English as a lingua franca. Language Teaching, 44, 281-315.

Li, Y.-Y. (2006a). Negotiating knowledge contribution to multiple discourse communities: A doctoral student of computer science writing for publication. Journal of Second Language Writing, 15(3), 159-178.

Li, Y.-Y. (2006b). A doctoral student of physics writing for publication: A sociopolitically-oriented case study. English for Specific Purposes, 25(4), 456-478.

Li, Y.-Y., \& Flowerdew, J. (2007). Shaping Chinese novice scientists' manuscripts for publication. Journal of Second Language Writing, 16(2), 100-117.

Lillis, T., \& Curry, M. J. (2010). Academic writing in a global context. London, UK: Routledge.

Lillis, T., Hewings, A., Vladimirou, D., \& Curry, M. J. (2010). The geolinguistics of English as an academic lingua franca: Citation practices across English medium national and English medium international journals. International Journal of Applied Linguistics, 20(1), 111-135.

Mezek, S. (2013). Multilingual reading proficiency in an emerging parallel-language environment. Journal of English for Academic Purposes, 12, 166-179.

Miller, A., Taylor, S., \& Bedeian, A. (2011). Publish or perish: Academic life as management faculty live it. Career Development International, 16(5), 422-445.

Pascarella, E., \& Terenzini, P. (1991). How college affects students. San Francisco, CA: Jossey-Bass.

Salager-Meyer, F. (2008). Scientific publishing in developing countries: Challenges for the future. Journal of English for Academic Purposes, 7(2), 121132.

Shaw, P. (1991). Science research students' composing processes. English for Specific Purposes, 10(3), 189206.

Swales, J. (1990). Genre analysis: English in academic and research settings. Cambridge, UK: Cambridge University Press.

Swales, J. (2004). Research genres: Explorations and applications. Cambridge, UK: Cambridge University Press.

Swales, J., Feak, C., \& Hixson, V. (2000) English in today's research world: A writing guide. Ann Arbor, MI: University of Michigan Press.

Velikaya, E. (2008). Developing students' academic skills in a Russian context. In M. Krzanowski (Ed.), Current Developments in English for Academic, Specific and Occupational Purposes (pp. 267-273). Reading, UK: Garnet Education. 


\section{Appendix 1}

\section{Links to online resources detailing critical reading modes}

General critical reading ability is available at:

http://www.criticalreading.com/critical_reading.htm,http://ctl.utsc.utoronto.ca/twc/sites/default/files/ CriticalReading.pdf,http://www.writing.utoronto.ca/advice/reading-and-researching/critical-reading

Non-discipline specific reading mode is available at:

http://www.eecs.harvard.edu/ michaelm/postscripts/ReadPaper.pdf,http://www.skillsandethics.org/ wp-content/uploads/2011/05/Reading-a-journal-article-2010.pdf,https://www.york.ac.uk/media/biology/ documents/careers/critical_reading_handout.pdf

Discipline-specific reading mode is available at:

- reading in a particular discipline (http://faculty.ksu.edu.sa/77632/Documents/Critically\%20Reading\%20 Journal\%20Articles.pdf,http://www.ncbi.nlm.nih.gov/pubmed/7722677,http://nursing.uthscsa.edu/crrp/ content/intro.pdf

- selecting proper sources (http://qoo.by/2u32)

- reading for developing one’s research process (http://www.planta.cn/forum/files_planta/critical_reading making_sense_of_research_papers_in_life_sciences_and_medicine_205.pdf 